\title{
Desenvolvimento de Produtos sem \\ Glúten: Possibilidades Industriais
}

\author{
Gisela A. C. dos Santos; Isadora B. R. Machado; \\ Pâmella R.Nascimento \& Nástia R. A. Coelho
}

Objetivou-se desenvolver formulações de falso pão de queijo, bolacha salgada e massa de crepe sem glúten. Procurou-se substituir a farinha de trigo por ingredientes, como fécula de batata, polvilhos doce e azedo, amaranto, farinha de milho, farinha de arroz, amido de milho. Conclui-se que as amostras de bolacha salgada sem glúten alcançaram boa aceitação, principalmente, a amostra com amaranto. Os resultados mostraram que o falso pão de queijo é viável, industrialmente, ao menos sob o ponto de vista tecnológico. Para os crepes, sugere-se que sejam realizados estudos adicionais, tanto microbiológicos quanto de embalagem, para definir parâmetros da vida de prateleira.

Palavras-chave: glúten; desenvolvimento; panificação.

This study aimed to develop formulations of fake cheese bread, crackers and pasta crepe gluten. Sought to replace wheat flour for ingredients such as potato starch, sweet and fermented cassava starch, amaranth, corn flour, rice flour, corn starch. We conclude that the gluten-free crackers samples achieved good acceptance, mainly the sample with amaranth. The results showed that the fake cheese bread is feasible industrially, at least from a technological point of view. For the pancakes, it is suggested that further studies are conducted, both microbiological as packaging, to define the shelf life parameters.

Keywords: gluten; development; bakery. 


\section{Introdução}

O desenvolvimento de novos produtos, sejam panificáveis ou não, exige que vários ingredientes sejam testados, a fim de identificar tanto a combinação quanto as quantidades desses, que gerarão melhores propriedades tecnológicas e sensoriais ${ }^{1}$. Nesse sentido, a aplicação da tecnologia de alimentos surge como alternativa e esperança para pessoas que precisam de produtos para dietas especiais.

A doença celíaca (DC) é uma intolerância à ingestão de glúten, contido em cereais como cevada, centeio, trigo e malte, em indivíduos geneticamente predispostos, caracterizada por um processo inflamatório que envolve a mucosa do intestino delgado, levando à atrofia das vilosidades intestinais, má absorção e uma variedade de manifestações clínicas ${ }^{2}$. O tratamento da doença é fundamentalmente dietético, caracterizando-se pela exclusão de alimentos fontes de glúten, mesmo nos períodos de latência, uma vez que esses tendem a ser transitórios ${ }^{3}$. Para garantir uma dieta isenta de glúten, o celíaco deve sempre conhecer os ingredientes que compõem as preparações alimentares e fazer leitura minuciosa dos ingredientes, listados nos rótulos de produtos industrializados ${ }^{4}$.

O glúten é uma substância elástica, aderente, insolúvel em água, responsável pela estrutura das massas alimentícias. É constituído por frações de gliadina e de glutenina que, na farinha de trigo, totalizam $85 \%$ da fração proteica. O trigo é o único cereal que apresenta gliadina e glutenina em quantidade adequada para formar o glúten, sendo essas as responsáveis por determinar características importantes na aceitação dos alimentos, afetando significativamente sua qualidade sensorial ${ }^{4}$.

A maior dificuldade na alimentação dos celíacos está no acesso aos produtos elaborados com substitutos da farinha de trigo que apresentem características sensoriais favoráveis e agradáveis ao consumidor. É possível encontrar no mercado alguns produtos sem glúten desenvolvidos a partir de cereais como o arroz e batata. $\mathrm{Na}$ sua maioria, não são produzidos em larga escala, o que representa agregação de valor comercial interessante para as indústrias ${ }^{3}$.

Os hábitos alimentares estão envolvidos com o sentimento dos indivíduos. Relacionam-se com valores familiares e culturais. Nesse aspecto, pode-se considerar que a restrição alimentar causa sofrimento, rompimento do afeto, perda do alimento. A experiência da doença impõe uma ruptura obrigatória de um hábito alimentar e a adesão a uma dieta isenta de glúten implica a adoção de novas práticas alimentares ${ }^{4}$.

Heisler et al. ${ }^{5}$ verificaram que a substituição da farinha de trigo pela farinha de arroz na merenda escolar teve uma aceitabilidade de 100\%. Segundo ele, a farinha de arroz é de rápida e fácil digestão no organismo, muito superior a do milho, o que a torna especialmente indicada para alimentos infantis, de idosos e pessoas com necessidades especiais de alimentação. Por não conter glúten, pode ser incluída na alimentação de pessoas com doença celíaca, sendo esta uma das grandes vantagens desta farinha.

César et al. ${ }^{6}$, no estudo 'Elaboração de pão de glúten', ao formularem um pão que pudesse ser consumido por pacientes celíacos, utilizando como base amilácea substituinte da farinha de trigo o creme de arroz e o polvilho doce, observaram no pão aparência e sabor característicos do pão tradicional. A casca ficou crocante e dourada, apresentando textura típica de pão. Entretanto, por não utilizar nenhum tipo de conservante no produto formulado, notaram o crescimento de bolores após quatro dias de armazenamento.

Carolino et al. ${ }^{7}$ na elaboração de nhoque de inhame sem glúten concluíram que é possível elaborar uma massa alimentícia sem glúten. Isso se dá pela associação de ingredientes à base de amido que atuam na substituição da farinha de trigo, juntamente às propriedades do inhame. Os resultados foram considerados satisfatórios, em relação à qualidade da massa e as características sensoriais, demonstrando aceitação pelos consumidores.

Um estudo realizado para a elaboração de massa alimentícia sem glúten com elevado teor proteico foi conduzido por Schmielei et al. ${ }^{8}$. Os resultados mostraram que o uso de isolado proteico de soja, albumina de ovo modificada e desidratada e farinha de arroz prégelatinizada são importantes para a obtenção de massas com características tecnológicas melhores que a amostra controle (somente com farinha de arroz). Obteve-se um produto final com menor tempo de cozimento, baixa perda de sólidos na água de cozimento e maior firmeza do que a amostra controle, características importantes neste tipo de produto. A adição de $17 \%$ de isolado proteico de soja, $15 \%$ de albumina de ovo modificada e desidratada 
e $15 \%$ de farinha de arroz pré-gelatinizada na farinha de arroz resultou em melhores condições tecnológicas, e os modelos matemáticos foram validados, podendo predizer as respostas analisadas pelo delineamento utilizado.

$\mathrm{Na}$ pesquisa realizada por Batista et al. ${ }^{9}$, foi desenvolvida farinha de inhame, com o objetivo de estudar a possibilidade de associação de ingredientes à base de amido que atuam na substituição da farinha de trigo, em produtos para celíacos. Em harmonia com as propriedades do inhame e técnicas de preparo adequadas, é possível obter resultados satisfatórios em relação à qualidade da massa e nas características sensoriais.

Segundo Monteiro ${ }^{10}$, a elaboração de disco de pizza pré-assado sem glúten e sem lactose, obteve aceitação de $70 \%$ de provadores não celíacos. Foram utilizadas diferentes proporções de farinha de arroz, inhame e quinoa como substituintes da farinha de trigo. Castro et al. ${ }^{11}$, visando melhorar a qualidade de vida de pacientes celíacos, oferecendo-lhes alternativas melhores em relação aos alimentos que visão compor sua dieta, desenvolveram biscoitos de queijo e bolos com grãos, flocos e farinha de quinoa. Foram criados biscoitos de queijo com flocos de quinoa, bolo de farinhas de milho e de quinoa e de bolo de banana com farinha de quinoa. De acordo com a análise sensorial, os dois primeiros se mostraram bem palatáveis, com textura e aroma agradáveis. Já a última preparação apresentou gosto amargo. Entretanto, concluíram ser viável a utilização de quinoa na substituição de produtos que contêm glúten, considerando-a de boa digestibilidade, o que evidencia sua qualidade proteica.

Kirinus et al. ${ }^{12}$, utilizando a farinha de soja e a de quinoa no preparo de macarrão caseiro sem glúten, constataram, por meio da avaliação sensorial, ser viável essa substituição. A maioria das pessoas que participou da análise sensorial demonstrou maior aceitação pelo macarrão elaborado com farinha de soja, relatando odor forte no macarrão elaborado com farinha de quinoa. Apesar disso, concluíram a viabilidade da elaboração do macarrão caseiro tanto com farinha de soja quanto farinha de quinoa. Devido a maior aceitação do macarrão com farinha de soja, esse pode ser sugerido como uma alternativa a mais na alimentação de pacientes celíacos.

Ferreira et al. ${ }^{3}$, no estudo 'Cookies sem glúten a partir da farinha de sorgo', concluíram a viabilidade da produção de biscoitos tipo cookies para celíacos. Segundo eles, a aceitação dos cookies de farinha de sorgo tanto pelos provadores não celíacos quanto pelos provadores celíacos foi considerada ótima. As formulações de cookies sem glúten apresentaram diferença estatística somente nos descritores sensoriais cor e odor. Quanto às análises físicas e químicas, apresentaram características próximas aos biscoitos feitos com farinha de trigo. Embora seja viável o consumo desses cookies, eles devem ser ingeridos moderadamente devido à densidade calórica e ao alto teor de fibras.

\section{Materiais e Métodos}

O desenvolvimento de todos os produtos foi realizado no laboratório de Panificação da Pontifícia Universidade Católica de Goiás (PUC), no Campus II, em Goiânia.

\section{FALSO PÃO DE QUEIJO}

Os experimentos foram realizados em três repetições.

Foram utilizados polvilho doce, azedo, fermento químico, sal e fécula de batata, além do aroma de queijo.

Todos os ingredientes secos foram pesados em uma balança (Balança 6270 - 5Kg Toledo) com auxílio de um béquer de $1000 \mathrm{~mL}$, colher e copo descartável. Procedeu-se a homogeneização dos ingredientes secos para posterior acréscimo dos outros componentes da formulação (água, óleo e ovos).

O preparo do falso pão de queijo foi completado com o acréscimo de ovos, água e óleo de soja, em quantidades estabelecidas para uma formulação tradicional. O óleo e a água foram fervidos, acrescidos a massa em pó para o escaldamento. Após o resfriamento da massa escaldada, foram acrescentados os ovos e todos os ingredientes foram misturados até obtenção de uma massa homogênea ${ }^{13}$. Após essa estapa, foram feitas bolinhas uniformes com as mãos untadas com óleo e colocadas em uma forma de alumínio própria para assamento. $\mathrm{O}$ forno deve ser preaquecido (20 minutos), e o tempo de assamento leva em torno de 30 minutos. Todas as operações foram realizadas de forma manual.

Os pãezinhos foram então colocados em forno elétrico pré-aquecido, marca Eletrolux, com temperatura de $180^{\circ} \mathrm{C}$ até aparentarem total assamento (aproximadamente 30 minutos), conforme recomendação de SILVA, GARCIA e FERREIRA ${ }^{14}$. 
Os produtos foram avaliados sensorialmente em termos de aparência, aroma, sabor, textura e presença de alvéolos internos.

\section{BOLACHA SALGADA}

Os materiais utilizados estão apresentados na Tabela 1

Tabela 1 - Formulações Testadas

\begin{tabular}{|c|c|}
\hline \multicolumn{2}{|c|}{ FORMULAÇÕES TESTADAS } \\
\hline Experimentos & Insumos \\
\hline $1^{\circ}$ Experimento & $\begin{array}{c}\text { Farinha de arroz, amido de } \\
\text { milho, óleo, sal e água. }\end{array}$ \\
\hline $2^{\circ}$ Experimento & $\begin{array}{c}\text { Farinha de arroz, fécula de } \\
\text { batata, óleo, sal e água. }\end{array}$ \\
\hline $3^{\circ}$ Experimento & $\begin{array}{c}\text { Farinha de arroz, água, farinha } \\
\text { de milho, margarina e sal. }\end{array}$ \\
\hline $4^{\circ}$ Experimento & $\begin{array}{c}\text { Amido de milho, água, amaranto } \\
\text { em flocos, margarina, farinha de } \\
\text { milho e sal. }\end{array}$ \\
\hline
\end{tabular}

Fonte: Nascimento ${ }^{15}$

As formulações, em percentual livre e sobre base de farinha (\% b.f.), estão apresentadas nas Tabelas 2 e 3.

Tabela 2 - Formulação da bolacha sem glúten amostra B

\begin{tabular}{|l|c|c|}
\hline Ingredientes & Peso(g) & \% b.f. \\
\hline Farinha de arroz & 73 & 100 \\
\hline Água & 180 & 391,3 \\
\hline Farinha de milho & 46 & 158,7 \\
\hline Margarina & 20,5 & 44,6 \\
\hline Sal & 2,5 & 5,44 \\
\hline
\end{tabular}

Fonte: URZÊDA ${ }^{16}$, citado por Nascimento ${ }^{15}$ adaptado.
Tabela 3 - Formulação da bolacha sem glúten amostra B

\begin{tabular}{|l|c|c|}
\hline Ingredientes & Peso(g) & \% b.f. \\
\hline Amido de milho & 46 & 100 \\
\hline Água & 80 & 174 \\
\hline Amaranto em flocos & 73 & 158,7 \\
\hline Margarina & 20,5 & 44,6 \\
\hline Farinha de milho & 17 & 37 \\
\hline Sal & 2,5 & 5,44 \\
\hline
\end{tabular}

Fonte: URZÊDA ${ }^{16}$, citado por Nascimento ${ }^{15}$ adaptado.

Os equipamentos usados na produção foram balança marca Shimadzu, modelo BL320H e balança marca C\&F, modelo P3, forno elétrico marca Layr, linha Crystal Plus e utensílios como: rolo de massa, espátula para bolo, colher.

\section{ANÁLISE SENSORIAL}

Os testes aplicados foram o de aceitação com uso da escala hedônica de 9 (nove) pontos, o teste de atitude com uso da escala (FACT) e o de preferência por ordenação.

A análise sensorial foi realizada em duas repetições: com voluntários que estavam presentes no Campus II da instituição. Participaram dos testes estudantes, professores, funcionários da PUC Goiás e funcionários da limpeza terceirizada. O número de provadores foi de 32 para a primeira repetição e para a segunda, foi de 31 provadores, para o teste de aceitação e intenção de compra. Para o teste de preferência, o número de provadores foi de 65 , sendo 32 na primeira repetição e 33 na segunda. A diferença entre os provadores dos testes de aceitação, intenção e preferência foi devido a alguns provadores terem respondido às fichas de avaliação de maneira inadequada, invalidando as fichas.

Cada provador recebeu duas amostras codificadas com números aleatórios de três dígitos, um copo com água para a limpeza do palato e as duas fichas de avaliação.

\section{CREPES}

Cinco formulações foram desenvolvidas, em três repetições, com o objetivo de identificar aquela que apresentasse melhores características sensoriais. 
Para o preparo de massa de crepe sem glúten, optouse por testar as seguintes farinhas: A - arroz (100\%); B - polvilho doce (50\%) e amido de milho (50\%); C polvilho doce (75\%) e polvilho azedo (25\%); D - amido de milho $(50 \%)$ e farinha de arroz $(50 \%)$ e E - farinha de $\operatorname{arroz}(50 \%)$ e polvilho doce $(50 \%)$. Para obtenção da massa de crepe pronta, foi necessário acrescentar a essas formulações outros ingredientes, como: ovo, leite, sal e óleo. Todas as massas foram preparadas em frigideira de material antiaderente, em fogão doméstico. Simulando o preparo pelo consumidor final.

Todas as formulações passaram por análise de perda de massa e determinação do teor nutricional. A análise da perda de massa foi feita da seguinte maneira: as massas de crepe, já 'assadas' foram acondicionadas em bandejas de isopor e recobertas com filme plástico de PVC (polivinilclorila) e armazenadas em temperatura de refrigeração e ambiente. A perda de massa foi determinada em balança marca Shimadzu, modelo BL320H, durante 7 (sete) dias para cada amostra, sob armazenamento em temperatura ambiente.

\section{Resultados e Discussões}

\section{FALSO PÃO DE QUEIJO}

Os resultados demostraram que a massa de falso pão de queijo comportou-se no escaldamento semelhantemente ao escaldamento do pão de queijo tradicional, no qual toda a massa seca ficou aglutinada e pouco pegajosa. APLEVICZ $^{18}$ comenta que na fabricação de produtos, nos quais o polvilho azedo é escaldado, proporciona ao produto sabor agradável, com crosta fina, crocante, maior volume, além de maior absorção em água. Segundo PIZZINATO $^{19}$, no processo de escaldamento, ocorre quebra de pontes de hidrogênio que mantêm o seu arranjo molecular, com isso, ocorre o fenômeno de hidratação e inchamento dos grânulos facilitando a gelatinização, formando uma pasta viscosa de amido.

Durante o amassamento da massa, esta teve uma boa homogenização. Todos os ingredientes se misturaram por completo, mantiveram uma textura de fácil manupulação e o tampo de mistura foi o mínimo possível para que a massa atingisse a consistência desejada. Observou-se que a massa não ficou aderida ao recipiente, no qual se realizou essa etapa e manteve uma maciez semelhante à formulação tradicional. Nesse processo, ocorre incorporação de certa quantidade de ar, que irá participar da expansão do volume e melhorar a textura do produto assado. No processo de amassamento, o ideal é que a massa não apresente textura seca (dura), nem pegajosa ${ }^{20}$.

Durante o processo de modelagem, a massa apresentou um despregar da colher com facilidade e uma fácil manipulação com as mãos, facilitando o processo de formação das bolinhas.

No processo de assamento, foi preciso ter cuidado com o tempo da preparação dentro do forno para que não ocorresse um endurecimento excessivo do produto. Nesta etapa, foi observado o escurecimento externo e o crescimento da massa. PIZZINATTO ${ }^{19}$ afirma que o aumento de volume do pão de queijo se deve à expanção de vapor e ar durante o assamento.

Como se trata de produto sem adição de leite nem queijo, a oferta de aminoácidos básicos, para ocorrência da Reação de Maillard, responsável pelo processo de escurecimento (não enzimático) no produto tradicional, fica praticamente reduzida ao que os ovos agregam à preparação. A cor amarelada do produto assado pode ser atribuída, nesse caso, à utilização de ovos caipiras na preparação.

Segundo SOUZA-SOARES e SIEWERDT ${ }^{21}$, o ovo tem propriedades de aeração e coagulação, fornecendo ao pão de queijo uma melhor estrutura, textura mais leve e aerada, maior volume e cor amarelada natural. Isso significa que a intensidade da cor de produto assado não será (e não foi) idêntica à que se observa na formulação de pão de queijo tradicional. Se o tempo de assamento for superior a 30 minutos, conforme observações experimentais para a formulação estudada, o produto apresentar-se-á extremamente seco e duro.

Com relação à aparência do falso pão de queijo, observou-se que houve presença de rachadura na parte superior do produto. Isso, provavelmente, deve-se à presença do polvilho azedo na formulação, conforme comentário feito por PEREIRA et. al. ${ }^{22}$, em que relata que pão de queijo produzido com polvilho azedo apresenta maior volume, textura mais porosa com maior número de células de ar, miolo esponjoso, mais leve e elástico, casca com rachaduras e uniforme quando comparado ao pão de queijo produzido com polvilho doce. MINIM et. al. ${ }^{23}$ relata também que formulações compostas por polvilho doce e azedo apresentam mais uniformidade, aroma e sabor. 
$\mathrm{O}$ aroma do falso pão de queijo foi muito semelhante ao que se observa no produto tradicional, tanto antes quanto durante o assamento. Entretanto, após o assamento, a intensidade do aroma sofreu redução significativa. Isso pode ser explicado pela presença de voláteis no aditivo. Como o assamento provoca perda de água e a maior parte das substâncias voláteis se liga à molécula de água, ocorre, invariavelmente, perda do aroma durante esta etapa.

Os falsos pães de queijo foram avaliados quanto à presença de alvéolos no interior do produto. Constatouse que os alvéolos estiveram presentes, mas não a ponto de provocarem o murchamento do produto após seu resfriamento. Segundo PIZZINATO ${ }^{19}$, essa formação de alvéolos é devido às trasformações que a massa sofre por causa da evaporação de uma pequena quantidade de água e a sua expansão (pela ação do vapor de água e dos gases) durante o assamento.

O sabor apresentou-se leve e discreto, devido à perda de substâncias voláteis do aroma durante o assamento, ou seja, ficou inferior ao do produto tradicional. KECHICHIAN ${ }^{24}$ relata que durante o processamento geralmente há perda parcial ou total do aroma em muitos alimentos

\section{CREPES}

Os resultados do processamento indicaram que o comportamento em termos de textura, quesito maciez, dificuldade para virar na frigideira e sabor, variou entre as amostras testadas. No quesito 'dificuldade para virar' foi observado que a amostra $\mathrm{B}$ (polvilho doce 50\% e amido de milho 50\%) foi a que apresentou maior dificuldade, sendo a amostra A, feita exclusivamente com farinha de arroz, a que apresentou maior facilidade para virar na frigideira. Ainda no quesito 'dificuldade para virar', as amostras D, C e E ficaram em segundo, terceiro e quarto lugar, respectivamente. Durante o corte das massas de crepes, foi observado que as amostras B e $\mathrm{C}$ apresentavam elasticidade. As demais apresentavam textura macia. Schamne, Dutcosky, Demiate ${ }^{25}$ desenvolveram pães sem glúten e muffins usando farinha de arroz e milho e amido de mandioca, visando uma boa aceitação sensorial e bom valor nutritivo. O uso de amido de mandioca, nas formulações de pão, foi restrito a um máximo de $50 \%$ da quantidade de farinha utilizada devido às limitações tecnológicas desse, entre elas, a produção de miolo pegajoso. Notaram, ao final da produção, que o amido de mandioca foi o produto amiláceo que mais influenciou na elasticidade do pão sem glúten. Todas as amostras apresentaram sabor agradável. Em relação à perda de massa, foi observado que as massas de crepe, armazenadas em temperatura ambiente, apresentaram uma maior perda de massa em relação àquelas armazenadas em temperatura de refrigeração. Para os produtos armazenados em temperatura ambiente, observou-se a presença de bolores no quarto dia de armazenamento (formulações $\mathrm{A}, \mathrm{B}, \mathrm{C}, \mathrm{D}$ e E). Isso se deve ao fato de que a velocidade de ocorrência das reações de deterioração é maior em temperatura ambiente do que em temperatura de refrigeração. Quanto ao teor nutricional das amostras, notou-se que as formulações que possuem farinha de arroz são as que apresentam maior valor calórico, entretanto, também são as que apresentam maior quantidade de proteína e de fibra.

\section{Conclusões}

\section{FALSO PÃO DE QUEIJO}

Conclui-se que a formulação testada resulta em falso pão de queijo com aparência muito semelhante à do produto original. A semelhança do produto assado com o produto tradicional permite afirmar que é viável a fabricação industrial deste produto, ao menos sob o ponto de vista tecnológico. No quesito aroma, sugere-se que sejam testadas novas concentrações, ou combinação de aromas de diferentes marcas, para verificar a permanência do aroma após o assamento.

Sugere-se que sejam realizados testes físico-químicos e microbiológicos para verificação da qualidade e validade do produto seco, além da realização de testes com embalagens apropriadas.

\section{BOLACHA SALGADA}

Conclui-se que as bolachas salgadas sem glúten desenvolvidas neste trabalho foram bem avaliadas sensorialmente, sendo que a formulação A, com amaranto, foi mais bem avaliada com $63,5 \%$ das respostas favoráveis a aceitação do produto.

\section{CREPES}

Com relação às formulações testadas, conclui-se que 
aquela elaborada exclusivamente com farinha de arroz foi a mais viável, tanto sensorial quanto tecnologicamente, porque perdeu menos massa durante o armazenamento em temperatura ambiente, ficando em segundo lugar no caso do armazenamento em temperatura de refrigeração. Sugere-se que sejam realizados estudos adicionais, tanto microbiológicos quanto de embalagem, para definir com maior exatidão os parâmetros da vida de prateleira do produto.

\section{Referências}

1. Sosa, D.E.F.; Fariña, L.O.; Kottwitz, L.B.; Falconi, A.; Cerutti, E.; Araújo, C.; Pootz, E. Pão de queijo adicionado de concentrado proteico de soro. Segundo simpósio de inovação tecnológica, Faculdade Assis Gurgacz, Cascavel, 2003.

2. Silva, T.S.G.; Furlanetto, T.W. Diagnóstico de doença celíaca em adultos. Rev. Assoc. Med. Bras., São Paulo, v. 56, n. 1, 2010.

3. Ferreira, S.M.R.; Luparelli, P.C.; Schieferdecker, M.E.M.; Vilela, R.M. Cookies sem glúten a partir da farinha de sorgo. 2009. Departamento de Nutrição da Universidade Federal do Paraná, Brasil. 2009. 11.

4. Araújo, H.M.C.; Araújo, W.M.C.; Botelho, R.B.A.; Zandonadi, R.P. Doença celíaca, hábitos e práticas alimentares e qualidade de vida. Revista de Nutrição, Campinas, v.23, n.3, 2010. 467-474.

5. Heisler, G.E.R.; Antônio G. A.; Mouro R. S.; Viabilidade da substituição da farinha de trigo pela farinha de arroz na merenda escolar; Alimento Nutricional, Araraquara, v. 19, n3, 2008. 299306.

6. César, A.S.; Gomes, J.C.; Staliano, C.D.; Fanni, M.L.; Borges, M.C. Elaboração de pão sem glúten. Revista Ceres. Março/Abril. 2006. $150-155$.

7. Carolino, F.T.; Pulito, D.R.; David, M. Elaboração do nhoque de inhame sem glúten. Desenvolvimento do rótulo e propaganda do nhoque de inhame sem glúten. $5^{\circ}$ Simpósio de Ensino de Graduação. $5^{\text {a }}$ Mostra Acadêmica Unimep. Universidade Metodista de Piracicaba. 2007.

8. Schmielei, M.; Jaekel, L.Z.; I Ishidai, P.M.G.; Chang, Y.K.; Stell, C.J.S. Massa alimentícia sem glúten com elevado teor proteico obtida por processo convencional. Ciência Rural, Santa Maria, v.43, n.5, 2013. 908-914.

9. Batista, V.; Ramos, C.S.S.; Silva, W.D.F.; Cardoso, M.R.V.; Carlos, F. G. Farinha de Inhame (Dioscorea Sp.): Uma Alternativa Para Celíacos. I Jornada Cientifica e VI FIPA do CEFET Bambuí, Bambuí, 2008. 4.

10. Monteiro, S. Z. Utilização de mesclas de farinha de arroz, inhame e quinoa na elaboração de disco de pizza pré-assado sem glúten e sem lactose. 2013. 82.

11. Castro, L.I.A.; Vila Real, C.M., Pires, I.S.C.; Pires, C.V.; Pinto, N.A.V.D.; Miranda, L.S.; Rosa, B.C.; Dias, P.A. Quinoa
(Chenopodium Quinoa Wildd): digestibilidade in vitro, desenvolvimento e análise sensorial de preparações destinadas a pacientes celíacos. Alim. Nutr., Araraquara. v.18, n.4, out./dez. 2007. 413-419.

12. Kirinus, P.; Copetti, C.; Oliveira, V.R. Utilização de farinha de soja (Glicine Max) e de quinoa (Chenopodium Quinoa). Alim. Nutr., Araraquara. v.21, n.4, out./dez. 2010. 555-561.

13. Junior, W.Q.; Araújo, M.R.; Mendonça, A.L. Desenvolvimento de pão de queijo utilizando farinha de arroz. Estudos, Goiânia, v. 36, n. $5 / 6,2009.827-834$.

14. Silva, M.E.; Garcia, G.K.S.; Ferreira, H.F. Caracterização química, física e avaliação da aceitação de pão de queijo com baixo teor energético. Alimentação e Nutrição, Araraquara, v.14, n. 1, p. 69-75, 2003.

15. Nascimento, P. R. Desenvolvimento de bolacha sem glúten. 2015.60 f. Trabalho de conclusão de curso (Graduação em Engenharia de Alimentos) - Curso de Engenharia de Alimentos, Pontifícia Universidade católica, Goiânia, 2015.

16. Urzêda, A. R. Desenvolvimento de novos produtos para celíacos com o uso de farinha de trigo mourisco. 2010. Trabalho de conclusão de curso (Graduação em Engenharia de Alimentos) - Curso de Engenharia de Alimentos, Pontifícia Universidade Católica, Goiânia, 2010. 29.

17. Minim, V.P.R. Análise sensorial: estudo de consumidores. Viçosa: Universidade Federal de Viçosa, 2006.

18. Aplevicz, K.S.; Demiate, I.M. Análises físico-químicas de prémisturas de pães de queijo e produção de pães de queijo com adição de okara. Ciência e agrotecnologia, v. 31, n. 5, set./out., 2007. 1416-1422.

19. Pizzinato, A. Processo de fabricação de pão de queijo. Instituto de tecnologia de alimentos. Seminário páo de queijo: ingredientes, formulção e processo. Campinas: ITAL, 2000, 87-101.

20. Pereira, J. Caracterização química, física, estrutural e sensorial do pão de queijo. 2001. Tese (Dourado em Ciência dos Alimentos) Universidade Federal de Lavras, Lavras, 2001.222.

21. Souza-soares, 1.a.; siewerdt, F. Aves e Ovos. Universidade Federal de Pelotas, Pelotas, 2005. 138.

22. Pereira, J.; Ciacco, I.C.F.; Vilela, F.R.; Pereira, R.G.F.A. Função dos ingredientes na consistência da massa e nas características do pão de queijo. Ciência e Tecnologia de Alimentos, Campinas, v. 24, n. 4, Oct./Dec. 2004.

23. Minim, V.P.R.; Machado, P.T.; Canavesi, E.; Pirozi, M.R. Perfil sensorial e aceitabilidade de diferentes formulações de pão de queijo. Ciência e Tecnologia de Alimentos, Campinas, v. 20, n. 2, May/Aug. 2000.

24. Kechichian, V. Seminário Pão de Queijo: ingredientes formulação e processo. Instituto de tecnologia de alimentos, Campinas, 2000.

25. Schamne, C.; Dutcosky, S.D.; Demiate, I.M. Obtention and characterization of gluten-free baked products. Ciência e Tecnologia de Alimentos, Campinas, v. 30, n. 3, 2010. 


\section{Artigo Geral 23}

26. Santos, G.A.C. Desenvolvimento de massa de falso pão de queijo. Trabalho de conclusão de curso (Graduação em Nutrição) - Curso de Nutrição, Pontifícia Universidade Católica, Goiânia, 2012. 27.

\section{Gisela A. C. dos Santos; Isadora B. R. Machado; Pâmella R. Nascimento \& Nástia R. A. Coelho*}

Pontifícia Universidade Católica de Goiás - Escola de Engenharia de Alimentos - Avenida Universitária, número 1440, Setor Universitário, Goiânia, Goiás, Brasil, CEP 74605-010.

*E-mail: nastiacoelho@gmail.com 